\title{
The Moderating Effect of Mental Health in Familiarity Bias and Self-Attribution of Financial Planning Behaviour among Malaysians
}

\author{
LEY SEE TAN ${ }^{1}$, AUDREY LI CHIN LIM ${ }^{2}$, YEH YING CHEAH ${ }^{3}$ \\ ${ }^{1}$ Faculty of Business, MULTIMEDIA UNIVERSITY, MALAYSIA. E-mail: leyseetan@hotmail.com \\ ${ }^{2}$ Faculty of Business, MULTIMEDIA UNIVERSITY, MALAYSIA. E-mail: Iclim@mmu.edu.my \\ ${ }^{3}$ Faculty of Business, MULTIMEDIA UNIVERSITY, MALAYSIA. E-mail: yycheah@mmu.edu.my
}

\begin{abstract}
The growth of ageing population with prolonged life expectancy, decreased morbidity and cost of inflation rate among many countries have triggered huge socioeconomic challenges. Malaysia is expected to be labelled as the ageing nation in 2035 and thus, financial planning rests on the personal responsibility of many Malaysians. Financial planning behaviour is not only affected by economic living standard; mental health is one of the predictor variables in financial preparedness. This paper attempts to shed light on the intricacies in the relationships among familiarity bias, self-attribution bias and the mental health in financial planning behaviour among Malaysians by revisiting the Prospect Theory. Individuals who are mentally healthier tend to ignore risks as they get more comfortable and familiar with a particular stock when making decisions in financial planning. Investors who are self-attribution bias are more inclined to have high optimism towards their own capability and abilities under different circumstances moderated by their mental health. For instance, young working adults in Malaysia who have better mental health disposition are found to be overoptimistic and neglect the importance of financial planning.
\end{abstract}

Keywords: Mental Health, Self-Attribution Bias, Familiarity Bias, Financial Planning

JEL Classification: C1, L2 


\section{Introduction}

Financial planning which involves the process of saving, spending, healthcare planning, investing and retirement planning is increasingly important in view of the upward growth of ageing population among many countries. Advanced medical healthcare and improved healthy lifestyle have contributed to prolonged life expectancy, decreased morbidity and cost of inflation rate among the countries and thus, triggering huge socioeconomic challenges for both individuals as well as the policy maker. The life after retirement among the individuals may be affected significantly if they fail to be ready for their personal finance, incur high indebtedness and wrongfully estimate their life spans as documented in the previous studies. This is also evident among the older generation who is not given provision for social protection in Malaysia.

Among the Asian countries, the population of Japan is considered as an advanced ageing and shrinking population. It is predicted to decrease from 127 million to 109 million from 2017 to 2050 (Biswas, 2018). The overall population of Japan is likely to decrease rapidly due to the decline of fertility rate and decline of elderly population rate. The elderly population is assumed to grow rapidly from 41.9 million to 46.1 million from 2015 to 2050 (Biswas, 2018). Demand for long term healthcare and shrinking labour workforce due to ageing issues is on the rise. Therefore, it challenges the Japanese's financial planning regarding pension preparedness, personal savings, investment planning and healthcare insurances.

Based on Nga and Yeoh (2018) and Today (2016), inevitably, Malaysia is going to experience ageing population problem by 2050 with regards to the healthcare technology revolution and advancement of the medication industry. Improvement in the quality of life has also led to the rise in the longevity of Malaysians. Based on data given by the Department of Statistics Malaysia, life expectancies of most Malaysian males and females are 72.2 years and 77.3 years in 2019 compared to 72.1 years and 77.0 years in 2016 (Mahidin, 2019). It indicates that Malaysians will be at risk of becoming an 'ageing nation' when the rate of Malaysians who aged 65 years and above reach $7 \%$ according to the definition set by the World Health Organization. In view of the higher life expectancy among Malaysians, serious actions and steps should be taken by Malaysians to plan for their finance in terms of income savings, investment portfolio, healthcare insurances, spending habits and retirement portfolio.

The majority of labour workforces in Malaysia are hired by private sectors (Economic Planning Unit, 2015). Employees Provident Fund (EPF) is a government agency that helps private industry workers to plan for savings and retirement pensions. The mandatory retirement age set by Malaysian Government schemes had altered since 1951 which was originally 55 to 60 years old in 2012(Hussein, 2019). The Employees Provident Fund (EPF) had introduced "Akaun Emas" as a second retirement account for EPF members who can only withdraw money when the members reach the age of 60 (EPF, 2016). Besides, the pensions in a normal account can still be withdrawn at the age of 55. Other than that, Private Retirement Schemes is a voluntary long-term investment retirement scheme which was launched in 2012 to help Malaysians in preparing for their retirement as part of their financial planning process. Malaysians who are aged 20 to 31 had been given RM 1000 as incentives to encourage them to start saving in the early stage with the minimum of RM 1000 in 2018. However, argument about the sufficiency of PRS arises as it does not guarantee on the capital sum invested and dividends received as well as the funds are not allowed to be taken out in a short period of time (The Star, 2013; Gomes, 2019). Therefore, self-awareness among Malaysians on how to wisely plan for their finance in order to achieve their financial goals in life is crucial.

\subsection{Problem Statement}

Financial planning behaviour is a fundamental concept of personal financial well-being and it is the persistent habits that need to be developed in the early stage of life to ensure a comfortable life in future. However, several studies show that Malaysians have poor performance in financial planning (Faezah, Talib, \& Manaf, 2017; Hassan, Rahim, Ahmad, Tengku Zainuddin, Merican \& Bahari, 2016; Mahdzan, Mohd-Any, \& Chan, 2017). As mentioned earlier, financial planning behaviour encompasses 
saving behaviour, spending behaviour, investing behaviour, healthcare planning behaviour and retirement planning behavior among the individuals in the process of financial planning. Hence, financial planning is a vital and a daunting task for many individuals. The effects of poor financial planning are evident in past studies that have documented the bankruptcy of over 80,000 Malaysians since 2015 due to the high indebtedness (Carvalho, Sivanandram, Rahim, \& Tan, 2019).

Specifically, about 78 percent of Malaysians do not have enough funds for retirement since most retirees have withdrawn their retirement savings fully from the EPF in about three to five years after 55 years old according to the data provided by Malaysian Healthy Ageing Society (MHAS) (Today, 2016). It clearly indicates that Malaysians fail to manage their financial planning. Other than that, Malaysia was ranked as one of the countries in the world as having the highest household debt to income ratio according to the McKinsey report in 2015. Moreover, seven countries including Netherlands, South Korea, Canada, Sweden, Australia and Thailand are reported as high household debt countries besides Malaysia (McKinsey, 2015, Qureshi, Muhammad Imran, et al. 2020) .

Past research had discussed the issues raised by the familiarity bias which affects the process of decision making and financial behaviour in different fields (Smith, 2012; Baker \& Ricciardi, 2015; Edna, Rajan, \& Abdullah, 2017). In addition to this, people tend to make choices in familiar investment settings whereby they are more comfortable on what is familiar to prevent ambiguity and unknown risks. Therefore, most people tend to overinvest in their employer stocks without looking into the implications of risks of those stocks and thus, revealing a serious lack of diversification in their portfolio. Apart from that, self-attribution bias is one of the psychological biases that influences people to be overoptimistic in their own capabilities under different circumstances. The younger generation in Malaysia are found to ignore the importance of financial planning in their 20s as they are overoptimistic in thinking that they are far too young for financial planning. They tend to experience stress when they are asked to plan for long term with regards to finance-related matters. On the other hand, individuals who are in their 30s or 40s, are found to be overconfident in thinking that they are prepared for their retirement with Employee Provident Fund (EPF) savings. Besides this, individuals who are in their 50s feel depressed when they finally realise that their pension fund is insufficient to maintain their desired quality of life (Moorthy, Chelliah, Chiau, Lai, Ng, Wong, \& Wong, 2012).

In addition to this, mental health problems are found to incur RM 14.46 billion of total Gross Domestic Product in Malaysia (Arumugam, 2020). An individual's perception towards income adequacy might be influenced subjectively as physical and mental health of an individual are found to have effects on their judgment bias. Therefore, Allen and Laborde (2017) suggest that mutual influences between mental health and financial planning need to be further explored. Further, Bogan and Fertig (2017) claim that mental health has significant negative impacts on one's savings. However, there is no evidence suggesting that savings are impacted by psychological distress through limited cognition and financial literacy. Studies in this area is rather limited in Asian countries especially in Malaysia. Hence, it is crucial to further explore the interrelationships among familiarity bias, selfattribution bias, mental health and financial planning behaviour by applying the Prospect Theory. The insights of this study are imperative to help policy makers in implementing policies or policy intervention such as imposing withdrawal penalties of defined contribution plans in Malaysia.

\subsection{Research Objectives}

Based on the discussion above, essentially, this study seeks to achieve the following research objectives:

1. To investigate the effects of mental health on the financial planning behaviour of Malaysians.

2. To investigate the effects of familiarity bias on the financial planning behaviour of Malaysians.

3. To investigate the effects of self-attribution bias on the financial planning behaviour of Malaysians.

4. To investigate the moderating effects of mental health on the familiarity bias in the financial 
planning behaviour of Malaysians.

5. To investigate the moderating effects of mental health on the self-attribution bias in the financial planning behaviour of Malaysians.

\section{Literature Review}

\subsection{Financial Planning Behaviour}

According to Thakur, Jain, and Soni (2017), financial planning behaviour is defined as personal capability to make rational finance decisions based on unbiased analysis with regards to saving, spending, investing and planning. Individual financial literacy and psychological biases influence significantly one's investment decision, pension contribution and commitment (Romanos, 2015). Almansour and Arabyat (2017) reveal that financial behaviour in terms of risk-seeking is influenced by the psychological biases such as heuristics bias, herding bias, loss aversion, regret aversion, mental accounting, stock market factors as well as self-attribution bias. However, inconsistent findings attributable to factors such as different cultural religiosity and government interventions are also evident in several studies that examine relationships among psychological biases and financial planning behaviour (Baker \& Ricciardi, 2015; Grable, Archuleta, Ford, Kruger, Gale, \& Goetz, 2020; Romanos, 2015).

\subsection{Mental Health}

In the discussion of new concepts of mental health by Galderisi, Heinz, Kastrup, Beezhold, and Sartorius (2015), one of the concepts states the importance of dynamic state of internal equilibrium. In other words, the changes in an individual's different life stages are required to achieve new mental equilibrium. Mentally healthy people are able to resiliently restore and achieve new mental equilibrium when facing adolescent crises, divorce, marriage and financial crisis in life for a period of time after experiencing adequate human emotions such as depression, anxiety, grief and fear. In contrast, people who suffer from mental health disorders and negative emotions are believed to make improper decisions. Further to this, Noone and the co-authors (2010) indicate that financial planning behaviour is not only affected by the economic living standard, mental health is found to be one of the predictor variables that could affect the financial preparedness in individuals. In the psychological field, Slavish, Scaglione, Hultgren, and Turrisi (2018) depict the role of mental health in modifying the relationships between the positive affections and negative affections in the decision-making process. Anxiety is also found to be a strong moderator in negatively affecting the relationships between the financial management behaviour and savings in the economic view (Garmendia, Topa, Herrador, \& Hernández, 2019).

\subsection{Familiarity Bias}

Familiarity bias has been recognized as one of the biases which supplants people' objective judgment criteria due to habit persistence (Constantinides, 1990). As a result, the decision making process is distorted while planning for finance-related matters. Besides this, past studies have reviewed the interconnectedness among familiarity bias, status quo bias, endowment effect and home bias when it comes to financial decisions(Baker \& Ricciardi, 2015; Clark, Duong, Gerrans, Lajbcygier, Moulang, Strydom, Vaz, \& Wickramanayake, 2013; Raghubir \& Das, 1999; Romanos, 2015). Taylor, Halen, and Huang (2018) define familiarity bias as a bias in which people like to stick with what they know in the past and stay in the comfort zones that make them feel safer. Familiarity bias occurs when people are averse to ambiguity, risk and uncertainty and refuse to change. As a result, people tend to spend less than what they earn in the financial planning process(Taylor, Halen, \& Huang, 2018). 


\subsection{Self-Attribution Bias}

Self-attribution bias, which is sometimes known as self-serving bias, occurs when an individual tends to attribute positive outcomes to their own intelligence and capability while blaming negative outcomes to the external forces. Past research illustrates the significance in the correlations among the self-attribution bias, confirmation bias, overconfidence bias and excessive optimism bias in making financial decisions ( Hoffmann \& Post, 2014; Ahmad et al., 2017; Zahera \& Bansal, 2018; Dewan \& Dharni, 2019) . Self-attribution bias builds up overconfidence bias and it motivates excessive optimism bias in the individual behaviour while making financial decisions (Kafayat, 2014; Peón, Antelo \& CalvoSilvosa, 2017; Zahera \& Bansal, 2018). Kafayat (2014) concludes that Pakistani investors of Islamabad Stock Exchange make suboptimal decisions that lead to undesirable outcomes as they suffer from selfattribution bias, overconfidence bias and excessive optimism bias. Additionally, studies find that individuals who suffer from one of the biases as mentioned earlier, are likely to suffer from another bias (Dewan \& Dharni, 2019). Self-attribution could also lead to overconfidence and thus, causing people to overtrade with low diversification in their portfolios (Hoffmann \& Post, 2014). Hence, it affects one's financial health as these psychological biases lead to high risk and underperform portfolios. Kafayat (2014) summarises that overconfidence in investor behaviour has led to excessive optimism and illusion of control. He further proves that this irrational behaviour exists when making financial decisions in stock trading. Investor tends to exaggerate their trading abilities and overweight the information collected in their favour.

\section{Methodology}

\subsection{Research Framework}

Past studies are reviewed to synthesise a framework to examine the effects of familiarity bias, selfattribution bias and mental health in financial planning behaviour among Malaysians.

Figure 3. 1 Research Framework

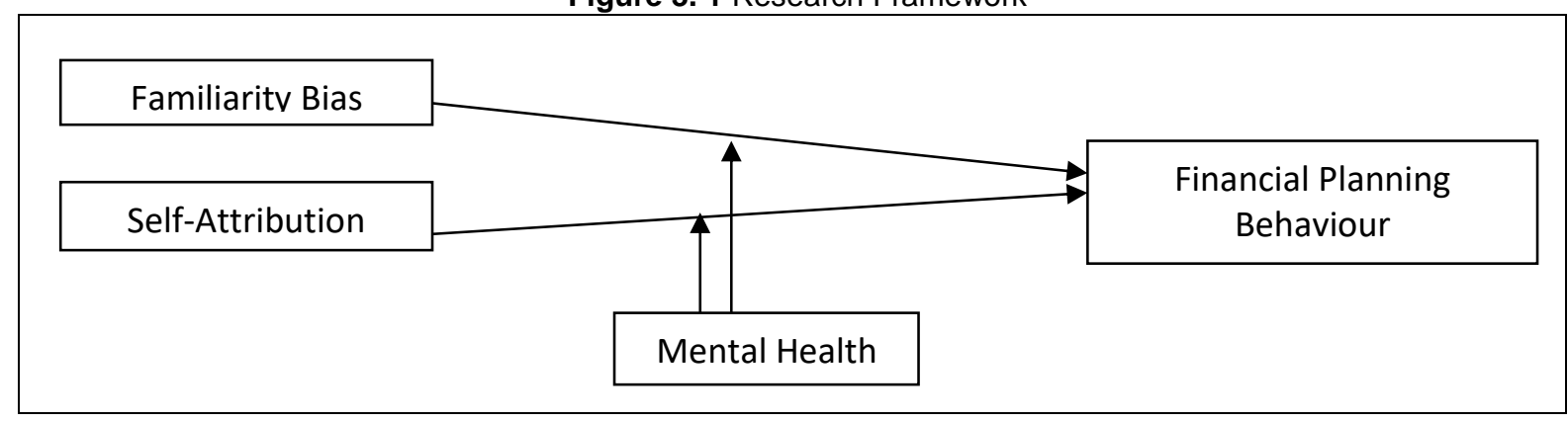

\subsection{Propositions Development}

\subsubsection{Mental Health and Financial Planning Behaviour}

Lerner and the co-authors (2014) stress that carryover effects may happen while there are emotions such as depression, anxiety, anger, sadness, fear or regret as moderators in the decision making process. Extensive literature shows that negative effects of emotions on decision making can be reduced as emotions and the psychological responses are sometimes short lived and quickly fade away (Levenson, 1999; Mauss, McCarter, Levenson, Wihelm, \& Gross, 2005). Therefore, the researchers were interested to explore the effect of mental health on financial decision making as it is vital in affecting people' motivation while investing for future return (Dave, Rashad, \& Spasojevic, 2011; Heraty \& McCarthy, 2015; Lee \& Kim, 2018). Moreover, Bogan and Fertig (2017) state that psychological distress such as depression and anxiety increase the probability of withdrawal from retirement accounts and reduce retirement savings in their financial assets. Hence, the following proposition is developed to explore the influence of mental health in Malaysians' financial planning behaviour: 
Proposition $_{1}$ : The financial planning behaviour of Malaysians is negatively affected by the mental health of Malaysians.

\subsubsection{Familiarity Bias, Mental Health and Financial Planning Behaviour}

Most employees prefer buying more stocks, allocating more assets and investments towards their company's stock due to familiarity bias(Clark et al., 2013). Therefore, problems arise when the employees lack portfolio diversification which makes their financial plan inferior and riskier(Baker \& Ricciardi, 2015; Borsch \& Andersen, 2014). Many employees are inactive in re-allocating their portfolios and stick to the familiar default choices even though there are unknown stocks with high potential returns which are more profitable, due to status quo bias (Clark et al., 2013; Raghubir \& Das, 1999). Various types of superannuation funds offered to individuals lead to poorer decisions and outcomes as too many choices resulting in confusion among investors who are overwhelmed due to status quo bias in making decisions(Clark et al., 2013). Byrne and the other researchers explain that home bias and local bias occur when people overweight their portfolios in domestic assets and invest in familiar local securities in which they perceive as less risky and more profitable. This has resulted in sub-optimal portfolios(Byrne \& Utkus, 2007; Byrne, Blake, \& Mannion, 2010; Baker \& Ricciardi, 2015).

In the aspect of preferences in risk averse and risk taking behaviour due to familiarity bias, behavioural genetics and traits as well as experimental economics to define the correlation of genetic traits and economic decision making have been studied(Cesarini, Daves, Johannesson, Lichtenstein, \& Wallace, 2009; Frydman, Camerer, Bossaerts, \& Rangel, 2011; Soo Hong, Ebstein, \& Songfa, 2012). Soo Hong et al. (2012) explain that the serotonin, as a neurotransmitter for emotional regulation could influence mood and thus, when emotions become imbalanced, anxiety and depression could be induced. Previous neuroimaging studies have proved that the association between serotonin transporter and activation in amygdala affect risk aversion and familiarity bias (Canli \& Lesch, 2007; Soo Hong et al., 2012). Reduced greater volume of amygdala and functional connectivity of amygdalamPFC while processing negative emotion such as anxiety, fear and depression may lead to low risk tolerance and risk avoidance during decision making(Dodhia, Hosanagar, Fitzgerald, Labuschagne, Wood, Nathan \& Phan, 2014; Marek, Strobel, Bredy, \& Sah, 2013; Motzkin, Philippi, Wolf, Baskaya, \& Koenigs, 2015; Satterthwaite, Cook, Bruce, Conway, Mikkelsen, Satchell, Vandekar, Durbin, Shinohra, \& Sheline, 2016). However, mental health as a moderator, moderating the relationships between familiarity bias and financial planning behaviour among Malaysians remains unexplored despite an impressive volume of past studies conducted in the western countries.

In view of this, the following propositions are developed to clarify the relationships among mental health, familiarity bias and Malaysians' financial planning behaviour:

Proposition $_{2}$ : The financial planning behaviour of Malaysians is negatively affected by the familiarity bias of Malaysians.

Proposition ${ }_{3}$ : The financial planning behaviour of Malaysians is positively affected by the moderating effects of mental health on the familiarity bias of Malaysians.

\subsubsection{Self-Attribution Bias, Mental Health and Financial Planning Behaviour}

Extensive literature proves that people used to be self-protective when facing bad outcomes and tend to self-enhance themselves when the outcomes associated with their decision are favourable. (Miller \& Ross, 1975). Thus, researchers conclude that individuals attribute their favourable financial performances to their personal skills and undesired outcomes to misfortune (Ahmad et al., 2017; Hoffmann \& Post, 2014; Zahera \& Bansal, 2018). Beshears, Choi, Laibson, \& Madrian (2018) further explain that people are reluctant to face unrealised losses as they perceive losses as more painful and thus, making changes slowly while cutting losses. Prior research also indicates that cultural differences in Western countries have a higher tendency of self-attribution bias compared to Eastern countries(Mezulis, Abramson, Hyde, \& Hankin, 2004; Mukku, Harbishettar, \& Sivakumar, 2018). The 
existence of a high level of underperformed trading activities in equity markets is revealed to have significant relationship with the presence of overconfidence (Dewan \& Dharni 2019).

From the perspectives of psychology, self-attribution bias is a self-defence mechanism to protect people' self-esteem and externalise their own responsibility (Mezulis et al., 2004; Zahera \& Bansal, 2018). People with low self-esteem are believed to have high levels of depression compared to people with high self-esteem (Montesano, Feixas, Caspar, \& Winter, 2017). Past psychology research has proved that people who are suffering from depression and anxiety tend to have lower self-attribution bias compared with people who are mentally healthy (Mezulis et al., 2004). Baker and Ricciardi (2015) also discover that personal emotion is one of the elements that induce excessive optimism, overreaction, overconfidence, risk taking and vice versa. According to the psychology research done by Knee and Zuckerman (1996), one's personality moderates the self-attribution bias. An individual who possesses excessive optimism gains more unfavourable outcomes compared to the individual who is defensively pessimistic. Less to none research has discussed how mental health moderates the relationship between self-attribution bias and financial planning behaviour in Asian countries.

Therefore, the following propositions are developed to shed some light on the relationship among mental health, self-attribution bias and financial planning behaviour among Malaysians:

Proposition ${ }_{4}$ : The financial planning behaviour of Malaysians is negatively affected by the selfattribution bias of Malaysians.

Proposition ${ }_{5}$ : The financial planning behaviour of Malaysians is positively affected by the moderating effects of mental health on the self-attribution bias of Malaysians.

\section{Findings}

Individual who are suffered from high level of familiarity bias are found to make conservative decisions in their financial plan; have potential of misinterpreting information due to trust, greed and fear of change and fail to respond to ever changing environment (Clark et al., 2013; Peón et al., 2017; Taylor et al., 2018). The young working adults in Malaysia who have better mental health disposition are found to be overoptimistic and neglect the importance of financial planning. In addition to this, individuals who are mentally healthy may be more susceptible to familiarity bias besides selfattribution bias due to the influence of optimism bias when making financial planning decisions. Men who are mentally healthy under the influence of higher levels of self-attributed bias associated with optimism bias in financial planning may invest in assets that they are familiar with due to familiar bias. These behaviours are in line with evidence documented by extensive behavioural finance research and psychology research pertaining to risk-taking characteristics of men in dealing with their finance. Further to this, men are considered as heavy risk-taker as compared to women in making financial decisions (Ahmad et al., 2017). Past researchers state that active and extravert investors who have open-to-experience behaviour are engaging in higher levels of overconfidence and excessive optimism (Kubilay \& Bayrakdaroglu, 2016).

On the other hand, previous research has proved that people who are suffered from depression and anxiety tend to have lower self-attribution bias compared with people who are mentally healthy (Mezulis et al., 2004). Apart from this, mental health issues often alter personal financial decisions in terms of higher discount rates in which an individual expects lesser future utility and discounts their money in investing lesser illiquid assets that can only be assessed in future. This has resulted in greater risk aversion in which people invest more money in safer and lower risk assets(Bogan \& Fertig, 2017). Furthermore, about 5,500 respondents with mental health issues had been surveyed in 2016 and the figure is shown below. The targeted respondents proved that their financial planning and spending behaviour changed drastically over poor mental health(Moneyandmentalhealth.org, 2019). Poor mental health status is associated with memory issues and a high degree of impulsivity, which lead to financial decision-making difficulties and irrational financial decision while processing complex financial information. 
Figure 1: Percentage of Financial Planning Behaviour among the People with Poor Mental Health Status (\%)

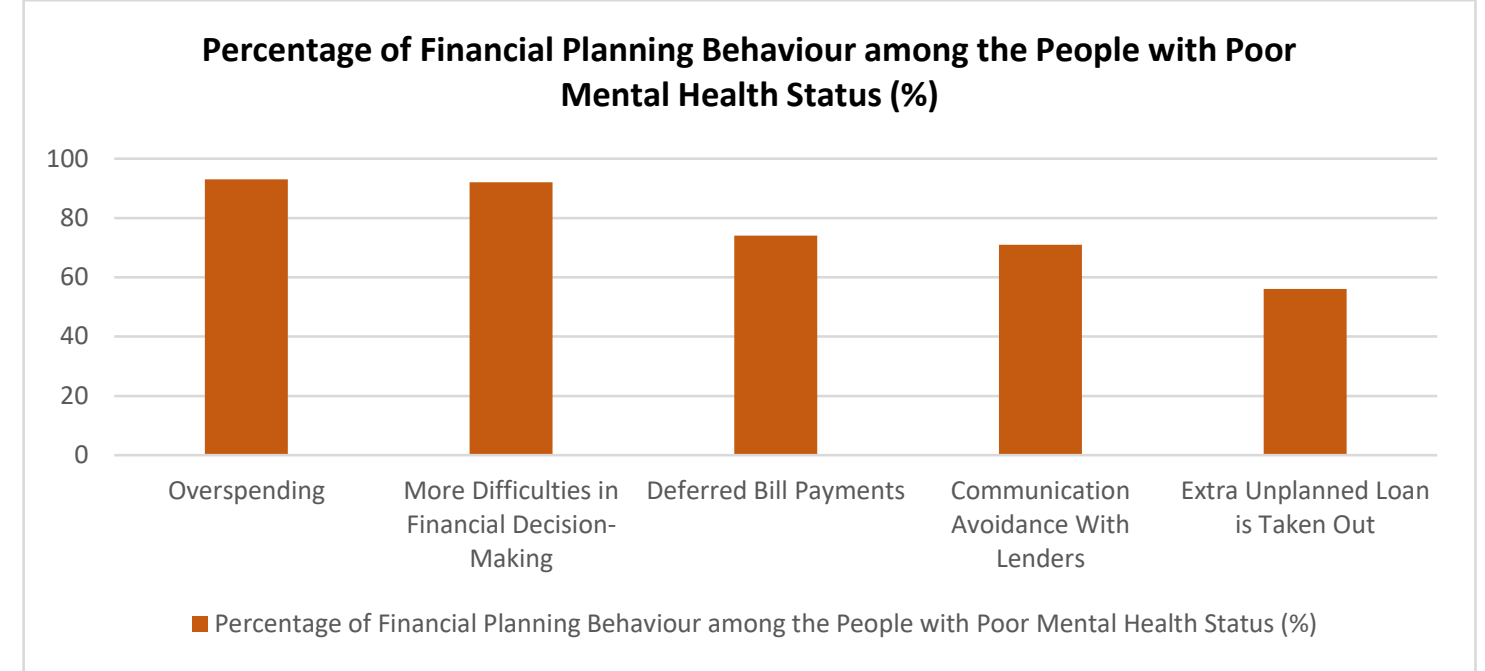

Source: Money and Mental Health Policy Institute (2019)

The insights of this study are imperative to create awareness on the importance of having a positive mental health among the individuals. This study also illustrates individual's vulnerability to potential psychological biases in the decision making process. Hence, having a good understanding of the effects of these psychological biases and mental health could help them to make better decisions while achieving their goals pertaining to finance-related matters. The policy maker and pension scheme provider could also then formulate policies and offer schemes that are more attractive to Malaysians in financial planning before and after retirement.

\section{Conclusion}

Although financial planning behaviour has been studied in different contexts, the role of mental health as a moderator in individual financial planning behaviour is still left unexplored. Undoubtedly, the personal mental health problem is neglected by most Malaysians and to the fact that people are noticeably pessimistic towards financial planning. This has resulted in irrational financial risk-taking behaviour. The elderly generation is typically influenced by the culture of relying on the younger generations financially in Malaysia. Therefore, the increased dependency ratio of a country pressures the family members itself and a nation's economy. To date, there are very limited studies that have discussed mental health as a moderator moderating the relationship between familiarity bias, selfattribution bias and financial planning behaviour in western countries. The discussion on this topic especially in Asian countries including Malaysia is also very limited. The traits and the characteristics of financial planning behaviour among Malaysians could be varied with other countries due to different country's characteristics. Other than that, the quantitative method, specifically, survey method would be used in this study. Future researcher is suggested to apply different measurement and methodology, e.g. qualitative method and focus group interview to obtain more insightful result. Thus, having a good grasp of the interrelationships among the variables in this study could potentially assist the policymaker in creating more attractive policies for the betterment of Malaysian in financial planning.

\section{Acknowledgement:}

This research work is supported by the Fundamental Research Grant Schemes (FRGS) (MMUE/180032) 


\section{References}

1. Ahmad, Z., Ibrahim, H., \& Tuyon, J. (2017). Institutional investor behavioral biases: syntheses of theory and evidence. Management Research Review, 40(5), 578-603. https://doi.org/10.1108/MRR-04-2016-0091

2. Allen, M. S., \& Laborde, S. (2017). Five factor personality traits and inflammatory biomarkers in the English longitudinal study of aging. Personality and Individual Differences, 111, 205-210. https://doi.org/10.1016/j.paid.2017.02.028

3. Almansour, B. Y., \& Arabyat, Y. A. (2017). Investment decision making among Gulf investors: behavioural finance perspective. International Journal of Management Studies, 24(1), 41-71.

4. Baker, H. K., \& Ricciardi, V. (2015). Understanding Behavioral Aspects of Financial Planning and Investing. Journal of Financial Planning, 28(3), 22-26.

5. Bashir, T., Jaed, A., Ali, U., Meer, U., \& Naseem, M. (2013). Empirical Testing of Hweuristics Interrupting the Investor's Rational Decision Making. European Scientific Journal, 9(28), 432-444. https://doi.org/10.1109/GLSV.1998.665223

6. Beshears, J., Choi, J. J., Laibson, D., \& Madrian, B. C. (2018). Behavioral Household Finance. Handbook of Behavioral Economics, 177-276. https://doi.org/10.1016/bs.hesbe.2018.07.004

7. Biswas, S. (2018). Spotlight on Retirement: Japan. Secure Retirement Institute, 1-55.

8. Bogan, V. L., \& Fertig, A. R. (2013). Portfolio choice and mental health. Review of Finance, 17(3), 955-992. https://doi.org/10.1093/rof/rfs016

9. Bogan, V. L., \& Fertig, A. R. (2017). Mental health and retirement savings: Confounding issues with compounding interest. Health Economics (United Kingdom), 27(2), 404-425. https://doi.org/10.1002/hec.3579

10.Borsch, A., \& Andersen, N. (2014). Behavioral Traps and Innovation What innovators can learn from investors' failures. Deloitte Review, (15), 134-145.

11.Byrne, A., Blake, D., \& Mannion, G. (2010). Pension plan decisions. Review of Behavioral Finance, 2(1), 19-36. https://doi.org/10.1108/19405979201000002

12.Byrne, A., \& Utkus, S. P. (2007). Behavioural finance Understanding how the mind can help or hinder investment success. Vam-2013-05-08-0790, 1-32. Retrieved from https://www.vanguard.co.uk/documents/portal/literature/behavourial-finance-guide.pdf

13.Canli, T., \& Lesch, K. P. (2007). Long story short: The serotonin transporter in emotion regulation and social cognition. Nature Neuroscience, 10(9), 1103-1109. https://doi.org/10.1038/nn1964

14.Cesarini, D., Dawes, C. T., Johannesson, M., Lichtenstein, P., \& Wallace, B. (2009). Genetic variation in preferences for giving and risk taking. Quarterly Journal of Economics, 124(2), 809-842. https://doi.org/10.1162/qjec.2009.124.2.809

15.Clark, G., Duong, H., Gerrans, P., Lajbcygier, P., Moulang, C., Strydom, Vaz, J., \& Wickramanayake, J. (2013). A Review of Retirement Savings Investment Behaviours: Theory and Evidence. Australiancentre.Com.Au. Retrieved from http://australiancentre.com.au/sites/default/files/superannuation-cluster/cp3wp2-a-Review-ofRetirement-Savings-Investment-Behaviours.pdf

16.Constantinides, G. (1990). Habit formation: A resolution of the equity premium puzzle. Journal of Monetary Economics, 98(3), 519-. https://doi.org/10.1016/S0304-3932(02)00147-2

17.Dave, D., Rashad, I., \& Spasojevic, J. (2011). The Effects of Retirement on Physical and Mental Health Outcomes. SSRN Electronic Journal, (October). https://doi.org/10.2139/ssrn.1024475

18.Dewan, P., \& Dharni, K. (2019). Herding Behaviour in Investment Decision Making: A Review. Journal of Economics, Management and Trade, 24(2), 1-12. https://doi.org/10.9734/jemt/2019/v24i230160 
19.Dodhia, S., Hosanagar, A., Fitzgerald, D. A., Labuschagne, I., Wood, A. G., Nathan, P. J., \& Phan, K. L. (2014). Modulation of resting-state amygdala-frontal functional connectivity by oxytocin in generalized social anxiety disorder. Neuropsychopharmacology, 39(9), 2061-2069. https://doi.org/10.1038/npp.2014.53

20.Dr. Mohd Uzir Mahidin. (2019). Department of Statistics Malaysia Press Release Abridged Life Tables, Malaysia, 2015-2017. (July), 2015-2017.

21.Edna, M., Rajan, S., \& Abdullah, A. (2017). An Exploratory Review of Retirement Savings Investment Decisions: A Malaysian Perspective. An International Journal, 9(1s), 771-792.

22.Faezah, N., Talib, M., \& Manaf, H. A. (2017). Attitude towards Retirement Planning Behaviour among Employee's. Journal of Business and Management, 1(1), 15-21. Retrieved from https://www.ijbmjournal.com/uploads/2/6/8/1/26810285/004-ijbm-12-

17.pdf\%0Ahttp://www.ijbmjournal.com/uploads/2/6/8/1/26810285/nurul_15-21_.pdf

23.Frydman, C., Camerer, C., Bossaerts, P., \& Rangel, A. (2011). MAOA-L carriers are better at makingoptimal financial decisions under risk. Proceedings of the Royal Society B: Biological Sciences, 278(1714), 2053-2059. https://doi.org/10.1098/rspb.2010.2304

24.Galderisi, S., Heinz, A., Kastrup, M., Beezhold, J., \& Sartorius, N. (2015). Toward a new definition of mental retardation. World Psychiatry, 14(2), 231-233.

25.Garmendia, P., Topa, G., Herrador, T., \& Hernández, M. (2019). Does death anxiety moderate the adequacy of retirement savings? Empirical evidence from 40-plus clients of spanish financial advisory firms. International Journal of Financial Studies, 7(3). https://doi.org/10.3390/ijfs7030038

26.Grable, J. E., Archuleta, K. L., Ford, M. R., Kruger, M., Gale, J., \& Goetz, J. (2020). The Moderating Effect of Generalized Anxiety and Financial Knowledge on Financial Management Behavior. Contemporary Family Therapy, 42(1), 15-24. https://doi.org/10.1007/s10591-019-09520-x

27.Hassan, K. H., Rahim, R. A., Ahmad, F., Tengku, Z., Azira, N., Merican, R. R., \& Bahari, S. K. (2016). Retirement Planning Behaviour of Working Individuals and Legal Proposition for New Pension System in Malaysia. Journal of Politics and Law, 9(4), 43. https://doi.org/10.5539/jpl.v9n4p43

28. Heraty, N., \& McCarthy, J. (2015). Unearthing psychological predictors of financial planning for retirement among late career older workers: Do self-perceptions of aging matter? Work, Aging and Retirement, 1(3), 274-283. https://doi.org/10.1093/workar/wav008

29.Hoffmann, A., \& Post, T. (2014). Self Attribution Bias in Consumer Financial Decision-Making.

30.Hussein, N. (2019). The Malaysian Pension System. Nomura Journal of Asian Capital Markets, 3(2), 15-20.

31.Kafayat, A. (2014). Interrelationship of biases: effect investment decisions ultimately. Theoretical and Applied Economics, 21(6), 85-110.

32.Knee, C. R., \& Zuckerman, M. (1996). Causality orientations and the disappearance of the selfserving bias. Journal of Research in Personality, 30(1), 76-87. https://doi.org/10.1006/jrpe.1996.0005

33.Kubilay, B., \& Bayrakdaroglu, A. (2016). An Empirical Research on Investor Biases in Financial Decision-Making, Financial Risk Tolerance and Financial Personality. International Journal of Financial Research, 7(2). https://doi.org/10.5430/ijfr.v7n2p171

34.Lee, J., \& Kim, J. (2018). The Effect of Retirement on Health Behaviors, Mental Health and Subjective Health Status. Health and Social Science, 47(I), 5-29. https://doi.org/10.21489/hass.2018.04.47.5

35.Lerner, J., Li, Y., Valdesolo, P., \& Kassam, K. (2014). Emotions and Decision Making. Annual Review of Psychology, 53(9), 1689-1699.

36.Levenson, R. W. (1999). The intrapersonal functions of emotion. Cognition and Emotion, 13(5), 481504. https://doi.org/10.1080/026999399379159

37.Mahdzan, N. S., Mohd-Any, A. A., \& Chan, M. K. (2017). The influence of financial literacy, risk aversion and expectations on retirement planning and portfolio allocation in Malaysia. Gadjah 
Mada International Journal of Business, 19(3), 267-289. https://doi.org/10.22146/gamaijb.24441

38.Marek, R., Strobel, C., Bredy, T. W., \& Sah, P. (2013). The amygdala and medial prefrontal cortex: Partners in the fear circuit. Journal of Physiology, 591(10), 2381-2391. https://doi.org/10.1113/jphysiol.2012.248575

39.Mauss, I. B., McCarter, L., Levenson, R. W., Wilhelm, F. H., \& Gross, J. J. (2005). The tie that binds? Coherence among emotion experience, behavior, and physiology. Emotion, 5(2), 175-190. https://doi.org/10.1037/1528-3542.5.2.175

40.McKinsey \& Company. (2015). Debt and (not much) deleveraging. McKinsey Global Institute, (February), 1-136. Retrieved from https://www.mckinsey.com/ /media/McKinsey/Global Themes/Employment and Growth/Debt and not much deleveraging/MGI Debt and not much deleveragingFullreportFebruary2015.ashx

41.Mezulis, A. H., Abramson, L. Y., Hyde, J. S., \& Hankin, B. L. (2004). Is There a Universal Positivity Bias in Attribution? A Meta-Analytic Review of Individual, Developmental and Cultural Differences in the Self-Serving Attributions Bias. The American Psychological Association, 130(5), 711-747. https://doi.org/10.1037/0033-2909.130.5.711

42.Miller, D. T., \& Ross, M. (1975). Self-serving biases in the attribution of causality: Fact or fiction? Psychological Bulletin, 82(2), 213-225. https://doi.org/10.1037/h0076486

43.Moneyandmentalhealth.org. (2019). Money and mental health. In Money and Mental Health Policy Institute. https://doi.org/10.1176/appi.ps.660907

44.Montesano, A., Feixas, G., Caspar, F., \& Winter, D. (2017). Depression and identity: Are selfconstructions negative or conflictual? Frontiers in Psychology, 8(MAY), 1-10. https://doi.org/10.3389/fpsyg.2017.00877

45. Moneyandmentalhealth.org. (2019). Money and mental health. In Money and Mental Health Policy Institute. https://doi.org/10.1176/appi.ps.660907

46. Moorthy, K., Chelliah, T., Shu Sien, C., Chin Leong, L., Ze Kai, N., Choy Rhu, W., \& Yoke Teng, W. (2012). A Study on the Retirement Planning Behaviour of Working Individuals in Malaysia. International Journal of Academic Research in Economics and Management Sciences, 1(2), 54-72. https://doi.org/10.22038/ijorl.2017.20807.1775

47.Motzkin, J. C., Philippi, C. L., Wolf, R. C., Baskaya, M. K., \& Koenigs, M. (2015). Ventromedial prefrontal cortex is critical for the regulation of amygdala activity in humans. Biological Psychiatry, 77(3), 276-284. https://doi.org/10.1016/j.biopsych.2014.02.014

48.Mukku, S. S. R., Harbishettar, V., \& Sivakumar, P. T. (2018). Psychological morbidity after job retirement: A review. Asian Journal of Psychiatry, 37, 58-63. https://doi.org/10.1016/j.ajp.2018.08.003

49.Nga, K. H., \& Yeoh, K. K. (2018). An exploratory model on retirement savings behaviour: A Malaysian study. International Journal of Business and Society, 19(3), 637-659.

50.Peón, D., Antelo, M., \& Calvo-Silvosa, A. (2017). An inclusive taxonomy of behavioral biases. European Journal of Government and Economics, 6(1), 24. https://doi.org/10.17979/ejge.2017.6.1.4322

51.Qureshi, Muhammad Imran, et al. "Classifications of sustainable manufacturing practices in ASEAN region: A systematic review and bibliometric analysis of the past decade of research." Sustainability 12.21 (2020): 8950.

52.Raghubir, P., \& Das, S. R. (1999). A Case for Theory-Driven Experimental Enquiry. Financial Analysts Journal, 55(6), 56-79. https://doi.org/10.2469/faj.v55.n6.2314

53.Romanos, L. (2015). Behavioral Finance and Pension Decisions.

54.Satterthwaite, T. D., Cook, P. A., Bruce, S. E., Conway, C., Mikkelsen, E., Satchell, E., ... Sheline, Y. I. (2016). Dimensional depression severity in women with major depression and post-traumatic stress disorder correlates with fronto-amygdalar hypoconnectivty. Molecular Psychiatry, 21(7), 894-902. 
https://doi.org/10.1038/mp.2015.149

55.Slavish, D. C., Scaglione, N. M., Hultgren, B. A., \& Turrisi, R. (2018). An Ecological Momentary Assessment of Affect, Mental Health Symptoms, and Decisions to Drink Among First-Year College Women: A Pilot Study. Prevention Science, 20(5), 753-764. https://doi.org/10.1007/s11121-0180966-6

56.Smith, C. L. (2012). The Effects of Familiarity and Persuasion on Risk Assessment. Retrieved from https://commons.erau.edu/edt/131

57.Soo Hong, C., Ebstein, R. P., \& Songfa, Z. (2012). Ambiguity Aversion and Familiarity Bias : Journal of Risk and Uncertainty, 44(1), 1-18.

58.Taylor, T., Halen, N., \& Huang, D. (2018). Why Are Retirees Not Spending More ? Investments \& Wealth Institute, 40-52.

59.Thakur, S. S., Jain, S. C., \& Soni, R. (2017). Understanding individual retirement planning behaviour: An evidence from survey data. Journal of Commerce and Management Thought, 8(3), 399. https://doi.org/10.5958/0976-478x.2017.00023.4

60.Zahera, S. A., \& Bansal, R. (2018). Do investors exhibit behavioral biases in investment decision making? A systematic review. Qualitative Research in Financial Markets, 10(2), 210-251. https://doi.org/10.1108/QRFM-04-2017-0028 